OPEN ACCESS

Edited by:

Karine Portier,

Université de Lyon, France

Reviewed by:

Raphael Labens,

School of Animal and

Veterinary Sciences, Charles

Sturt University, Australia

Miguel Gozalo Marcilla,

Faculty of Veterinary Medicine of Botucatu, Brazil

${ }^{*}$ Correspondence: Alessandro Mirra alessandro.mirra@ vetsuisse.unibe.ch

Specialty section:

This article was submitted to

Veterinary Surgery and Anesthesiology,

a section of the journal Frontiers in Veterinary Science

Received: 21 September 2017

Accepted: 19 January 2018

Published: 07 February 2018

Citation:

Mirra A, Klopfenstein Bregger MD and Levionnois OL (2018) Suspicion of Postanesthetic Femoral Paralysis of the Non-Dependent Limb in a

\section{Suspicion of Postanesthetic Femoral Paralysis of the Non-Dependent Limb in a Horse}

\author{
Alessandro Mirra ${ }^{1 *}$, Micaël David Klopfenstein Bregger ${ }^{2}$ and Olivier Louis Levionnois ${ }^{1}$ \\ ${ }^{1}$ Division of Anesthesiology and Pain Therapy, Department of Clinical Veterinary Medicine, Vetsuisse Faculty, University of \\ Bern, Bern, Switzerland, ${ }^{2}$ Swiss Institute for Equine Medicine, Vetsuisse Faculty, University of Bern, Bern, Switzerland
}

A 15-year-old Selle Francais gelding was presented to the equine referral hospital for treatment of a left guttural pouch mycosis previously diagnosed. After induction, the horse was shortly hoisted by all four feet, moved on a padded surgical table, and positioned in right lateral recumbency. In order to reduce the risk of bleeding during surgical manipulation of the carotid and maxillary arteries, a mean arterial pressure between 60 and $70 \mathrm{mmHg}$ was targeted. After surgery, the horse was moved in a padded recovery box keeping the same lateral recumbency. Four unsuccessful attempts were performed, with the horse always returning to sternal recumbency keeping the left hind limb up. At the fifth attempt, performed 120 min after the end of the general anesthesia, the horse stood up correctly but moderate ataxia and absence of weight bearing on the left hind limb were shown. Both the stifle and the fetlock joint were held in a flexed position and could not be extended properly in order to set the foot on the ground, resulting in a very short step. The horse was calm, not sweating, and willing to move; the muscles of the affected limb were relaxed, and the limb was neither warm nor painful at palpation. Occasionally, the horse flexed the affected hind limb in an exaggerated motion with marked abduction. No additional laboratory analyses were performed. Due to a strong suspicion of neuropathy, a sling support was initiated and a supportive bandage associated with flunixine administration was performed until resolution of the symptoms. The horse fully recovered after 3 days. This case report does not clarify the pathogenesis of the possible postanesthetic neuropathy accounted on the non-dependent limb, highlighting the need for future research in this field. Non-dependent limb neuropathy should be an expected problem even after having ruled out the most commonly known causes predisposing to postanesthetic lameness.

\section{Keywords: femoral paralysis, non-dependent limb, postanesthetic, neuropathy, horse, complication}

\section{INTRODUCTION}

The present case reports the suspicion of postanesthetic femoral paralysis of the non-dependent limb in a horse, an unexpected occurrence, which may induce serious complications.

A 15-year-old Selle Français gelding, with a weight of $570 \mathrm{~kg}$ and a body condition score of 4/5 (1) was presented to the equine referral hospital for treatment of a left guttural pouch mycosis. Owner consent for publication of patient's data was obtained. The infection did not affect any arterial 
vessel and no bleeding had been reported by the owner or the private veterinarian. Surgery for arterial coil embolization was scheduled (2). Preanesthetic clinical examination revealed a heart rate (HR) of 28 beats/min, a respiratory rate (RR) of 16 breaths/ min, a rectal temperature of $37.3^{\circ} \mathrm{C}$, and pink mucous membrane with a capillary refill time of $1.5 \mathrm{~s}$. No abnormalities were detected on thorax auscultation and hematology and biochemistry were unremarkable. The horse had been treated for 2 days with local clotrimazol. Therefore, the patient was classified as an American Society of Anesthesiologist 2 category.

General anesthesia-related risks were considered and particular attention was placed on blood pressure management, with an aim to maintain a mean arterial blood pressure (MAP) between 60 and $70 \mathrm{mmHg}$ in order to reduce the risk of bleeding during surgical manipulation of the carotid and maxillary arteries.

As the animal was calm, a $14-\mathrm{G}$ catheter was placed without sedation in the left jugular vein. Acepromazine (Prequillan, Boehringer Ingelheim $\mathrm{GmbH}$, Switzerland) $\left(0.02 \mathrm{mg} \mathrm{kg}^{-1}\right)$ was administered intravenously (IV) $30 \mathrm{~min}$ before anesthesia induction. The horse was then moved into a padded induction box where xylazine (Xylasol, Graeub AG, Switzerland) $\left(0.6 \mathrm{mg} \mathrm{kg}^{-1}\right)$ and, immediately after, levomethadone (L-Polamivet, MSD Animal Health $\mathrm{GmbH}$, Switzerland) (0.05 $\left.\mathrm{mg} \mathrm{kg}^{-1}\right)$ were administered IV. Marked sedation was achieved within $10 \mathrm{~min}$. Anesthesia was induced in a swing gate with diazepam (Valium, Roche Pharma, Switzerland) (0.05 $\mathrm{mg} \mathrm{kg}^{-1}$ ) IV and ketamine (Ketasol, Graeub AG, Switzerland) (1.5 $\mathrm{mg} \mathrm{kg}^{-1}$ ) IV (mixed in the same syringe), and, after flushing the catheter with saline, thiopental (Thiopental Inresa, Ospedalia AG, Switzerland) (1.5 mg kg-1) IV. The trachea was intubated with a $28 \mathrm{~mm}$ internal diameter endotracheal tube. The horse was shortly hoisted by all four feet and positioned in right lateral recumbency onto a padded surgical table. Both hind limbs were positioned parallel to the ground on a specific padded support, with the coxofemoral joint positioned in its spontaneous natural angle. Anesthesia was maintained with isoflurane in oxygen-enriched medical air [fraction of inspired oxygen $\left(\mathrm{FiO}_{2}\right)=55 \%$ ] via a circle rebreathing system using an equine anesthetic machine (SurgiVet, Smiths medical, USA). Intravenous fluid therapy consisted of lactated Ringer's solution $\left(5 \mathrm{ml} \mathrm{kg}{ }^{-1} \mathrm{~h}^{-1}\right)$. A constant rate infusion of lidocaine (lidocaine 2\%, Streuli Pharma AG, Switzerland) was administered IV (1.8 $\mathrm{mg} \mathrm{kg}^{-1} \mathrm{~h}^{-1}$ ). Physiological variables [HR, RR, hemoglobin saturation by pulsoximeter, end-tidal partial pressure of carbon dioxide $\left(\mathrm{ETCO}_{2}\right)$, and invasive blood pressure] as well as $\mathrm{FiO}_{2}$ and end-tidal percentage of isoflurane were monitored continuously using a multiparameter monitor (Datex-Ohmeda S/5, Datex-Ohmeda, Finland) and recorded manually every $5 \mathrm{~min}$. A $20 \mathrm{G}$ arterial cannula was placed in the lateral metatarsal artery of the non-dependent limb (left). The transducer was zeroed to atmospheric pressure, positioned at the level of the heart, and a fast flush test confirmed normal damping of the system by visual observation.

Initial systolic (SAP), mean, and diastolic (DAP) arterial pressures measured approximately $30 \mathrm{~min}$ after anesthesia induction were 115,74 , and $87 \mathrm{mmHg}$, respectively. Isoflurane concentration was adjusted and a dobutamine IV infusion was prepared to be administered, if necessary. Although the horse maintained adequate $\mathrm{ETCO}_{2}$ in spontaneous ventilation, the breathing pattern was very irregular, and intermittent positive pressure ventilation was initiated $30 \mathrm{~min}$ after induction of anesthesia (tidal volume of approximately $6 \mathrm{l}$, RR of 7 breaths/min, peak inspiratory pressure of $12-15 \mathrm{cmH}_{2} \mathrm{O}$ ). At 1 and $2 \mathrm{~h}$ after induction of anesthesia, arterial blood was taken for gas analysis, revealing acceptable values ( $\mathrm{pH} 7.36$ and 7.33; partial pressure of carbon dioxide 58 and $60 \mathrm{mmHg}$, partial pressure of oxygen 134 and $130 \mathrm{mmHg}$; lactate 1.1 and $1.0 \mathrm{mmol}^{-1}$ ). The SAP, MAP, and DAP were maintained during the whole procedure between 82 and $98 \mathrm{mmHg}, 62$ and $70 \mathrm{mmHg}$, and 41 and $63 \mathrm{mmHg}$, respectively, without the assistance of dobutamine. General anesthesia and surgical procedure were uneventful, and lasted 190 and $145 \mathrm{~min}$, respectively. Lidocaine infusion was stopped 30 min before termination of anesthesia.

The horse was again shortly hoisted by all four feet, moved to the padded recovery box, and positioned in right lateral recumbency. Romifidine (Sedivet, Boehringer Ingelheim, Switzerland) (0.02 $\mathrm{mg} \mathrm{kg}^{-1}$ ) was administered in the recovery box through the venous catheter and the horse was left to recover unassisted. The horse swallowed $20 \mathrm{~min}$ after end of anesthesia (EA) and the trachea was extubated. Xylazine $\left(0.1 \mathrm{mg} \mathrm{kg}^{-1}\right)$ was administered IV twice at 10 and 15 min after EA because of marked nystagmus. A first unsuccessful attempt to stand was made 40 min after EA, followed by three further unsuccessful attempts. Each attempt was quiet and no injuries were suspected. The horse always returned to sternal recumbency, with the left leg always remaining the non-dependent one. It then stood up correctly on the fifth attempt, $120 \mathrm{~min}$ after EA. A recovery score of 2/5 [from 1 (best recovery possible) to 5 (worst recovery possible)] was attributed [following classification from Ref. (3)]. When standing, the horse showed moderate ataxia and absence of weight bearing on the left hind limb. Both the stifle and the fetlock joint were held in a flexed position and could not be extended properly in order to set the foot on the ground, resulting in a very short step. The horse was calm, willing to move, and not sweating; the muscles of the affected limb were relaxed, and the limb was neither warm nor painful on palpation. Occasionally, the horse flexed the affected hind limb in an exaggerated motion with marked abduction. No additional laboratory analyses were performed. As a result of the strong suspicion of neuropathy, a supportive bandage was applied to the left hind limb and the horse was provided sling support. Additionally, flunixine meglumine (Fluniximin, Graeub AG, Switzerland) (1.1 $\left.\mathrm{mg} \mathrm{kg}^{-1}\right) \mathrm{IV}$ was administered every $12 \mathrm{~h}$, as well as thiamine $\left(1.6 \mathrm{mg} \mathrm{kg}^{-1}\right)$ and pyridoxine $\left(0.7 \mathrm{mg} \mathrm{kg}^{-1}\right)$ IV every $24 \mathrm{~h}$ (Corébral, Vetoquinol AG, Switzerland). As the horse was judged able to stand without distress, the sling support was removed on the same evening. Weight bearing progressively improved on the following day without further complication, and complete resolution of lameness was observed the third postoperative day.

\section{BACKGROUND}

Mortality associated with equine anesthesia has been reported to occur in $0.8-1.8 \%$ of elective surgeries, with values rising to 
$19.5 \%$ in emergency cases despite improvements in anesthetic techniques and physiological monitoring (4). The largest mortality studies conducted to date in horse, the Confidential Enquiry into Perioperative Equine Fatalities 1 and 2 (5), reported that fractures and myopathy were responsible for $32 \%$ of postoperative mortality in non-colic surgeries. Myopathy may also occur alongside neuropathy, influencing the outcome and potentially increasing the risk of long bone fractures (4). Despite lack of pathognomonic symptoms, myopathy may be discriminated from neuropathy by presence of muscle stiffness and pain, leading eventually to fasciculation, sweating, and anxiety (6-8). Increased serum muscular enzymes and myoglobin, electromyography, ultrasonography, and nerve/muscular biopsy have been used to distinguish between the two conditions $(6,9-11)$, although clear differentiation between them can be challenging (8). Postanesthetic myopathy/neuropathy has been mostly reported in the dependent limbs. However, non-dependent forelimb neuropathy (12) and suspicion of bilateral femoral neuropathy have been reported (11). The occurrence of postanesthetic myopathy/ neuropathy has been hypothesized to be caused by decreased tissue perfusion and oxygenation $(8,9,12)$. The principal causes for their development are arterial hypotension, poor surgical table padding, and inappropriate positioning leading to regional blood flow disturbances, local compression, and mechanical tension on the nerves.

Recommendations have been made to avoid postanesthetic myopathy/neuropathy development $(8,9,13)$. The horse must be placed on the operating table in a position that does not put any part of its body under strain; regional venous outflow should be allowed and pressure increase within muscle bellies avoided. Limbs should be allowed to settle naturally and be secured without force. When the horse is lying in lateral recumbency, both non-dependent limbs should be supported parallel to the ground, and the dependent forelimb should be pulled forward to reduce pressure on it from the chest. If access to the medial side of the dependent forelimb is required, the upper forelimb can be flexed. When the horse is lying in dorsal recumbency, care should be taken if leg extension locking the patellae is required and procedures longer than 20 min should be avoided in this position. Padding helps to spread the weight of the horse over a larger area of the body and should be deep enough to prevent the body reaching the table. Finally, a MAP $>70 \mathrm{mmHg}$ has been recommended to ensure a good muscular perfusion, decreasing the incidence of postanesthetic myopathy (14). Same recommendations apply to the recovery phase but, for practical reasons, the legs generally lie on the floor without support.

\section{DISCUSSION}

Report of neuropathy of the non-dependent hind limb, like in the present case, has not been reported yet to the authors' knowledge.

Differentiation between myopathy and neuropathy can be challenging. They share common causes like arterial hypotension, poor padding of the surgical table, and inappropriate patient positioning, potentially leading to decreased tissue perfusion and oxygenation. Moreover, neuropathy and myopathy may occur in parallel. However, myopathy is generally associated with muscle stiffness, pain at palpation, sweating, and anxiety. In the present case, absence of these clinical signs led us to exclude a component of myopathy. Nerve compression and stretching with consequent nerve ischemia and hypoxia were suspected to be the most probable mechanism behind the observed dysfunction.

As the affected limb was the non-dependent one, factors such as the table padding and horse positioning, which were standard in the present case (8), were unlikely to be the causes of the problem. Hoisting by all four limbs could have potentially induced nerve stretching leading to neuropraxia, although to the author's knowledge, this has never been reported. The coxofemoral joint was positioned in its natural resting position, which should not lead to nerve damage.

Hypotension could have been a predisposing factor for the development of neuropathy. Because the non-dependent limb was elevated over the heart level, a decreased hydrostatic pressure could have led to a reduction of muscle perfusion. However, in the present case, the arterial line was placed in the affected limb, and the MAP was maintained between 62 and $72 \mathrm{mmHg}$ during the whole procedure, the lowest value being recorded during coil embolization. Therefore, intraoperative hypotension was unlikely to be the main cause of the postoperative complication. Since the arterial catheter was placed in the affected limb, good correlation between measured invasive blood pressure values and actual limb blood flow was expected. Dobutamine administration could have helped increasing femoral blood flow and possibly nerves perfusion (15-17). However, in equines, its effect on peripheral perfusion and microcirculation is still not well characterized (17-19).

In the present case, IV lidocaine was administered since the beginning of the surgical procedure. If ischemia was involved in the subsequent nerve dysfunction, its administration may have shortened normalization of the clinical condition; indeed, lidocaine has been shown to reduce reperfusion injury $(20,21)$.

The risk of developing postanesthetic myopathy/neuropathy increases with anesthesia duration (4). In the present case, the anesthesia lasted $190 \mathrm{~min}$, which could have contributed to the development of neuropathy. The horse required further $120 \mathrm{~min}$ to stand up after EA. However, the first attempt was made $40 \mathrm{~min}$ after EA, and the underlying femoral paralysis leading to ataxia may have made it difficult for the horse to reach a stable standing position. Development of the neuropathy during recovery seems unlikely since the unsuccessful attempts were all quiet and the horse always returned to sternal recumbency keeping the left hind limb as the non-dependent.

In the present case, the clinical presentation suggested a femoral paralysis, while myopathy was considered rather unlikely because there was lack of pain, sweating, restlessness, muscular stiffness, fasciculation, and anxiety when the horse recovered from anesthesia. However, further analyses could have been helpful in the diagnostic process. Unexpectedly, high plasma creatine kinase values within a few hours after surgery may support a diagnosis of myopathy (8). Nevertheless, the same enzyme may be elevated with other causes of postanesthetic lameness such as peripheral neuropathy, because of secondary muscle damage, or a mixed myopathy-neuropathy (9). Aspartate aminotransferase 
and myoglobin can also be elevated in cases of myopathy, with the latter leading to dark red or red/brown urine production (9). Hypoechoic areas within the muscle, when observed by ultrasonography, suggest muscle fiber disruption and acute injury (22) but the prognostic value of such observation is uncertain (6). Finally, muscle and nerve biopsy (11) and electromyography $(10,23)$ may distinguish between myopathy and neuropathy. However, in absence of local muscular symptoms, identifying a correct location to take the biopsy may be challenging. Moreover, changes associated with denervation are usually detectable by electromyography only 4-5 days after denervation (24, 25). Because of the strong suspicion of neuropathy, the fast improvement of the clinical condition and the low reliability of possible further investigations, no supplementary tests were conducted.

Different treatments have been described for postanesthetic myopathy/neuropathy $(6,8,9,11,12)$, but no clear guidelines have been established so far. In case of neuropathy symptomatic treatment with nonsteroidal anti-inflammatory agents, corticosteroids and dimethyl sulfoxide have been suggested to reduce neural edema. If the horse is able to stand, a supportive bandage and sling support could be applied. If needed, sedation and/or analgesia must be provided. In case a concomitant myopathy cannot be excluded, further treatment can be used. Dantrolene sodium has been described to relax muscles in cases with severe muscle stiffness. Fluid therapy should be initiated to prevent kidney dysfunction because of myoglobinurea. Acepromazine may

\section{REFERENCES}

1. Carrol CL, Huntington PJ. Body condition scoring and weight estimation of horses. Equine Vet J (1988) 20(1):41-5. doi:10.1111/j.2042-3306.1988. tb01451.x

2. Léveillé R, Hardy J, Robertson JT, Willis AM, Beard WL, Weisbrode SE, et al. Transarterial coil embolization of the internal and external carotid and maxillary arteries for prevention of hemorrhage from guttural pouch mycosis in horses. Vet Surg (2000) 29(5):389-97. doi:10.1053/jvet.2000.7537

3. Young SS, Taylor PM. Factors influencing the outcome of equine anaesthesia: a review of 1,314 cases. Equine Vet $J$ (1993) 25(2):147-51. doi:10.1111/j. 2042-3306.1993.tb02926.x

4. Dugdale AH, Taylor PM. Equine anaesthesia-associated mortality: where are we now? Vet Anaesth Analg (2016) 43:242-55. doi:10.1111/vaa.12372

5. Johnston GM, Eastment JK, Wood JLN, Taylor PM. The confidential enquiry into perioperative equine fatalities (CEPEF): mortality results of phases 1 and 2. Vet Anaesth Analg (2002) 29:159-70. doi:10.1046/j.1467-2995. 2002.00106.x

6. Webb JK, van Loon JPAM. The Incidence of Post Anaesthetic Myopathy (PAM) in Horses after General Anaesthesia for MTI in Comparison to the Incidence of PAM in Horses Anaesthetised for Other Reasons. Utrecht: University of Utrecht, Faculty of Veterinary Medicine (2013).

7. Auer JA, Stick JA. Equine Surgery, Chapter 21. 4th ed. Saint Louis: Elsevier Saunders (2012). p. 251-2.

8. Taylor PM, Clarke KW. Handbook of Equine Anaesthesia. Chapter 7. Philadelphia: Saunders Elsevier (2007). p. 137-52.

9. Young SS. Post anaesthetic myopathy. Equine Vet Educ (2005) 7:60-3. doi:10.1111/j.2042-3292.2005.tb01829.x

10. Wijnberg ID, Back W, De Jong M, Zuidhof MC, Van Den Belt AJM, van der Kolk JH. The role of electromyography in clinical diagnosis of neuromuscular locomotor problems in the horse. Equine Vet J (2004) 36:718-22. doi:10.2746/0425164044848019

11. Dyson S, Taylor P, Whitwell K. Femoral nerve paralysis after general anesthesia. Equine Vet J (1988) 20:376-80. doi:10.1111/j.2042-3306.1988. tb01550.x also improve lamellar blood flow, and anticoagulants (heparin, aspirin) have been suggested to prevent platelet aggregation and subsequent laminitis syndrome. Additionally, physiotherapy, massage, and ultraviolet light can be considered. In the present case, no signs of discomfort were shown by the animal and intense supportive therapy was not required.

\section{CONCLUDING REMARKS}

We report a strong suspicion of postanesthetic femoral paralysis of the non-dependent limb. This case report does not clarify the possible pathogenesis of the suspected nondependent limb postanesthetic neuropathy, highlighting the need for future research in this field. Adequate padding, prudent positioning, and good perfusion pressure must be always considered important factors for avoiding postanesthetic myopathy/neuropathy in horses.

\section{AUTHOR CONTRIBUTIONS}

$\mathrm{AM}, \mathrm{MK}$, and $\mathrm{OL}$ were involved in the care of the patient and were involved in planning this case report. AM was responsible for the conception of this case report and preparation of the first draft. MK and OL provided feedback and were involved in revising the manuscript. All the authors have read and approved the final version of the manuscript.

12. Oosterlinck M, Schauvliege S, Martens A, Pille F. Postanesthetic neuropathy/ myopathy in the nondependent forelimb in 4 horses. J Equine Vet Sci (2013) 33:996-9. doi:10.1016/j.jevs.2013.03.181

13. Duke T, Filzek U, Read MR, Read EK, Ferguson JG. Clinical observations surrounding an increased incidence of postanesthetic myopathy in halothaneanesthetized horses. Vet Anaesth Analg (2006) 33:122-7. doi:10.1111/j.14672995.2005.00189.x

14. Schauvliege S, Gasthuys F. Drugs for cardiovascular support in anesthetized horses. Vet Clin North Am Equine Pract (2013) 29(1):19-49. doi:10.1016/j. cveq.2012.11.011

15. Schier MF, Raisis AL, Secombe CJ, Hosgood G, Musk GC, Lester GD. Effects of dobutamine hydrochloride on cardiovascular function in horses anesthetized with isoflurane with or without acepromazine maleate premedication. Am J Vet Res (2016) 77:1318-24. doi:10.2460/ajvr.77.12.1318

16. Wang Y, Tang P, Zhang L, Guo Y, Wan W. Quantitative evaluation of the peripheral nerve blood perfusion with high frequency contrast-enhanced ultrasound. Acad Radiol (2010) 17:1492-7. doi:10.1016/j.acra.2010. 07.007

17. Raisis AL, Young LE, Blissitt KJ, Walsh K, Meire HB, Taylor PM, et al. Effect of a 30-minute infusion of dobutamine hydrochloride on hind limb blood flow and hemodynamics in halothane-anesthetized horses. Am J Vet Res (2000) 61:1282-8. doi:10.2460/ajvr.2000.61.1282

18. Dancker C, Hopster K, Rohn K, Kästner SB. Effects of dobutamine, dopamine, phenylephrine and noradrenaline on systemic haemodynamics and intestinal perfusion in isoflurane anaesthetised horses. Equine Vet J (2018) 50:104-10. doi:10.1111/evj.12721

19. Loughran CM, Raisis AL, Hosgood G, Secombe CJ, Lester GD. The effect of dobutamine and bolus crystalloid fluids on the cardiovascular function of isoflurane-anaesthetised horses. Equine Vet J (2017) 494:369-74. doi:10.1111/ evj. 12605

20. Lan W, Harmon D, Wang JH, Ghori K, Shorten G, Redmond P. The effect of lidocaine on in vitro neutrophil and endothelial adhesion molecule expression induced by plasma obtained during tourniquet-induced ischaemia and reperfusion. Eur J Anaesthesiol (2004) 21:892-7. doi:10.1017/ S0265021504000249 
21. Cassutto BH, Gfeller RW. Use of intravenous lidocaine to prevent reperfusion injury and subsequent multiple organ dysfunction syndrome. J Vet Emerg Crit Care (2003) 13(3):137-48. doi:10.1046/j.1435-6935.2003.00080.x

22. Valber SJ. Approach the horse with a suspected myopathy. World Equine Veterinary Association (WEVA), Proceedings of the 11th International Congress. Guarujá, SP, Brazil (2009).

23. Wijnberg ID, Franssen $H$. The potential and limitations of quantitative electromyography in equine medicine. Vet J (2016) 209:23-31. doi:10.1016/j. tvjl.2015.07.024

24. Cuddon PA. Electrophysiology in neuromuscular disease. Vet Clin North Am Small Anim Pract (2002) 32:31-62. doi:10.1016/s0195-5616(03)00079-2

25. van Wessum R, Sloet van Oldruitenborgh-Oosterbaan MM, Clayton HM. Electromyography in the horse in veterinary medicine and in veterinary research-a review. Vet Q (1999) 21:3-7. doi:10.1080/01652176.1999. 9694983

Conflict of Interest Statement: The authors declare that the research was conducted in the absence of any commercial or financial relationships that could be construed as a potential conflict of interest.

Copyright (c) 2018 Mirra, Klopfenstein Bregger and Levionnois. This is an open-access article distributed under the terms of the Creative Commons Attribution License (CC BY).The use, distribution or reproduction in other forums is permitted, provided the original author(s) and the copyright owner are credited and that the original publication in this journal is cited, in accordance with accepted academic practice. No use, distribution or reproduction is permitted which does not comply with these terms. 